\title{
Review
}

\section{The neurobiology of stress and gastrointestinal disease}

The role of stress in the modulation of the most common gastrointestinal disorders has traditionally been considered a domain of psychology, and has frequently been lumped together with the role of psychiatric comorbidity. Among clinicians, the term "stress" is generally taken as synonymous with psychological ("exteroceptive") stress. Based on the deeply ingrained Cartesian view in medicine and gastroenterology, stress and psychological factors have been considered fundamentally separate and unrelated to the "real" biological changes underlying organic disease. However, recent breakthroughs in the understanding of the neurobiology of the organism's response to acute and chronic stress, and the evolving understanding of elaborate brain-gut interactions and their modulation in health and disease, are beginning to require a reassessment of chronic stress in the pathophysiology and management not only of functional but also of "organic" gastrointestinal disorders.

Certain stressful life events have been associated with the onset or symptom exacerbation in some of the most common chronic disorders of the digestive system, including functional gastrointestinal disorders (FGD), inflammatory bowel disease (IBD), gastro-oesophageal reflux disease (GORD), and peptic ulcer disease (PUD). Even though methodological differences in reported studies which do and do not support such an association remain to be resolved, the association of sustained stressful life events preceding symptom exacerbation is based on several well designed surveys in patients with $\mathrm{FGD}^{1-4}$ with postinfectious irritable bowel syndrome (IBS), ${ }^{4}$ and with IBD. ${ }^{5-8}$ In addition, acute life threatening stress episodes in adult life (rape, post-traumatic stress syndrome) are an important risk factor in the development of functional gastrointestinal disorders. ${ }^{9}$ Finally, early life stress in the form of abuse plays a major role in the susceptibility of individuals to develop functional as well as IBD ${ }^{10-14}$ later in life. Thus, depending on the type of stressor, the lag time between the stressful event and the clinical manifestation or exacerbation of FGD or IBD may range from decades to weeks.

Even though the recent focus on Helicobacter pylori in the aetiology of PUD has nearly abolished the interest in the role of stress in PUD, there is considerable evidence that supports a role of stressful life events in the aetiology of PUD. ${ }^{15-21}$ Furthermore, more than $80 \%$ of $H$ pylori infected individuals (and the majority of non-steroidal antiinflammatory drug (NSAID) users) never develop an ulcer, while at least $10 \%$ of non-NSAID related peptic ulcers are not infected with $H$ pylori. ${ }^{22}$ It is intriguing to speculate on the role of certain life stressors as risk factors which determines which $H$ pylori positive individual actually develops an ulcer and which patients develop symptoms of dyspepsia instead, without an ulcer.

In contrast with FGD, IBD, and PUD, the epidemiological evidence to support a causal relationship between life events and disease activity in GORD is less conclusive. The primary information on the role of stressful life events is based on a population based survey in which $64 \%$ of patients with GORD indicated that stress increased their symptoms. ${ }^{23}$ GORD patients who are anxious and are exposed to long periods of stress are more likely to notice stress induced symptom exacerbation. ${ }^{24}$

\section{Stress response: defence of homeostasis at the cost of allostasis}

Stress, defined as acute threats to the homeostasis of an organism, ${ }^{25-27}$ be they real (physical) or perceived (psychological), and whether posed by events in the outside world or from within, evokes adaptive responses which serve to defend the stability of the internal environment and to assure the survival of the organism. ${ }^{28}$ Surprisingly, despite the wide range of different types of stressors, some of the principal circuits underlying the stress response under these different circumstances are remarkably similar. ${ }^{28}$ However, while the pathways involved in the activation of hypothalamic effector neurones during interoceptive stressors (gut infection, mucosal inflammation, internal haemorrhage) may be conceived as simple reflex responses, mediated at a subcortical level by the system involved in the processing of visceral information, exteroceptive stressors (psychological) engage circuits in the limbic forebrain, including the lateral and medial prefrontal cortex, hippocampus, and amygdala. ${ }^{28}$ Involvement of cortical circuits plays an important role in adjusting the stress response to the context, the physiological state of the organism, memories of past stressful life events, and beliefs about the subjective meaning of the situation.

Elaborate neurobiological response systems have evolved to orchestrate an integrated response which is best suited to respond to a specific stressor in a given situation for a specific individual. This ability to defend homeostasis (that is, to maintain stability) through change has been referred to as allostasis. ${ }^{29}$ In the healthy individual, the physiological response systems are rapidly turned on and off, synchronising the physiological stress response to the duration of the stressor, and limiting the exposure time of the organism to the potentially harmful effects of the stress response. However, there are several situations in which the severity or chronicity of the stressor and the ensuing physiological response systems can cause damage, exacerbate existing disease processes, or predispose the individual to acquire new diseases-that is, become maladaptive. This is particularly true in situations where the responsiveness of physiological responses to stress and the ability to adapt has already been altered due to genetic ${ }^{30}$ or early life events, ${ }^{31}$ thereby biasing an individual's susceptibility to the negative effects of stress throughout life. These long term effects of the organism's accommodation to certain types of stress have been referred to as allostatic load, ${ }^{32}$ the "wear and tear" resulting from chronic overactivity or underactivity of physiological stress response systems. Stressors which have been associated with such maladaptive consequences, both acute and chronic, are referred to in this review as pathological stressors. The outcome of pathological stress on the patient is determined not only by the length, sever-

\footnotetext{
Abbreviations used in this paper: FGD, functional

gastrointestinal disorders; IBD, inflammatory bowel disease; GORD, gastro-oesophageal reflux disease; PUD, peptic ulcer disease; IBS, irritable bowel syndrome; NSAID, non-steroidal anti-inflammatory drug; TNF- $\alpha$, tumour necrosis factor $\alpha$; IL, interleukin; HPA, hypothalamic-pituitary-adrenal; CRH, corticotropin releasing hormone; CRF, corticotropin releasing factor; PVN, paraventricular nucleus; GCs, glucocorticoids.
} 
ity, and type of stressor, but also by other factors, such as genetics, early life experiences, cognitive factors, and environmental support.

\section{Physical and psychological stressors}

Systemic or interoceptive stressors ${ }^{28}$ in the context of the four chronic gastrointestinal disorders listed above, can occur in the form of mucosal inflammation (IBD, PUD) or tissue irritation by excessive acid exposure (GORD). Inflammatory cytokines, including tumour necrosis factor $\alpha$ (TNF- $\alpha$ ), interleukin (IL)-1, and IL-6 cause acute stimulation of the hypothalamic-pituitary-adrenal (HPA) axis alone or in synergy. ${ }^{33}$ The cytokine mediated stimulation is mediated through stimulation of corticotropin releasing hormone (CRH; or corticotropin factor, CRF) and arginine vasopressin release from hypothalamic neurones, and by direct effects at the pituitary and adrenocortical levels. Different mechanisms, including cytokine stimulation of vagal afferents, have been proposed by which the cytokine signal crosses the blood-brain barrier. ${ }^{28}$ The ultimate output of peripheral cytokine stimulated HPA axis activation, plasma cortisol, is the principal negative feedback mediator to shut off both the inflammatory response as well as HPA axis activation. In contrast with the effects of acute inflammation, several animal experimental ${ }^{34}{ }^{35}$ and human studies in patients with certain chronic inflammatory disorders, such as rheumatoid arthritis, have provided evidence for a blunting of the HPA axis response. ${ }^{34}{ }^{36-38}$ This blunting appears to be secondary to downregulation of $\mathrm{CRH}$ gene expression and $\mathrm{CRH}$ secretion by mediators associated with chronic inflammation.

Psychological or exteroceptive stressors fall into different categories, depending on the individual's age during stress exposure, severity and chronicity of the stressor, and the subjectively perceived threat. For example, several different types of psychological stressor can have permanent consequences on the responsiveness of the individual to stress and chronic disease later in life: (1) Early life stress in the form of altered mother-infant interaction during a species specific "window" of development has been shown to result in permanent hypersecretion of CRF and overactivity of the locus coeruleus. ${ }^{31}$ (2) Chronic abuse (physical or sexual) and neglect throughout life have been found to be associated with alterations in the HPA axis response to stress. $^{39-41}$ (3) Exposure to a one time stressor which is perceived by the individual as life threatening (rape, combat situation, natural disaster) resulting in post-traumatic stress syndrome ${ }^{42}$ with alterations in sympathetic and HPA axis responses to stress and to exaggerated memory recall of the traumatic event. ${ }^{43}$ Chronic stressors in adult life (such as losses, financial threats, etc), in particular when sustained and perceived as threatening, may result in transient reversible alterations in allostatic systems, which in the case of IBS have been shown to result in exacerbation of IBS symptoms. ${ }^{3}$ It is primarily these latter types of pathological stressors that have been addressed in the epidemiological studies mentioned earlier.

\section{How are stressors translated into integrative physiological responses?}

While the traditional concept of stress has focused on subjective conscious feelings, thoughts, beliefs, and memories reported by some individuals in association with stressful life events, the major breakthroughs in this area have occurred through an understanding of the biological mechanisms which are responsible for the detrimental effect of certain stressful life events on health. The focus of this review is on these biological mechanisms and their

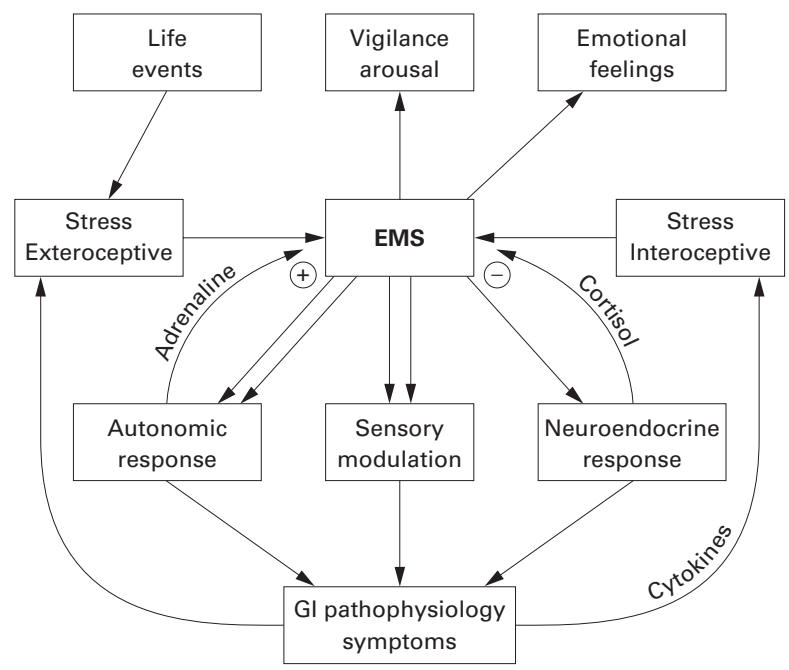

Figure 1 Emotional motor system (EMS) pathways.

implications, while the reader is referred to the extensive cognitive literature. ${ }^{44-48}$

The organism's response to stress is generated by a network comprised of integrative brain structures, in particular subregions of the hypothalamus (paraventricular nucleus, PVN), amygdala, and periaqueductal grey. These structures receive input from visceral and somatic afferents and from cortical structures. Cortical inputs include the medial prefrontal cortex, and subregions of the anterior cingulate and insular cortices. ${ }^{28}{ }^{49} 50$ In turn the integrative network provides outputs to the pituitary and pontomedullary nuclei, which in turn mediate the neuroendocrine and autonomic output to the body, respectively. ${ }^{28} 4649$ This central stress circuitry is under feedback control via ascending monoaminergic projections from these brain stem nuclei, in particular serotonergic (raphe nuclei) and noradrenergic (including locus coeruleus) nuclei, and via circulating glucocorticoids (GCs), which exert an inhibitory control via central GC receptors located in the medial prefrontal cortex and hippocampus. ${ }^{34}$ The parallel outputs of this central circuitry ("emotional motor system") ${ }^{51}$ which is activated in response to various stressors include responses of the autonomic nervous system, the HPA axis response, the endogenous pain modulation system, and ascending aminergic pathways. These pathways are summarised in fig 1 .

One important chemical mediator of the central stress response is CRH (and probably related, currently unknown molecules) located in certain effector neurones of the PVN, the amygdala, and locus coeruleus complex. ${ }^{52}$ $\mathrm{CRH}$ secretion by PVN neurones is under positive feedback regulation by central noradrenergic pathways (including those originating from the locus coeruleus), thereby forming a bidirectional positive feedback loop between the CRH-noradrenergic systems. ${ }^{53}$ Central injection of $\mathrm{CRH}$ can reproduce behavioural and physiological responses similar to those seen in response to acute psychological stress, ${ }^{55}$ and inhibition of CRF mediated responses by antagonists ${ }^{56}$ or in knockout animals results in a decrease in the animal's response to stress. ${ }^{58} 59$

\section{Modulation of physiological stress responses by allostasis}

The responsiveness and output pattern of this network is likely to be under partial genetic control ${ }^{3060}$ and shows considerable plasticity in response to early life events ${ }^{31}$ and to certain types of pathological stress..$^{61}{ }^{62}$ For example, studies in animals and humans have clearly demonstrated that certain types of pathological stress can alter the 
responsiveness of feedback systems by downregulation of pre and/or postsynaptic receptors (adrenergic, serotonergic, GC receptors) ${ }^{6162}$ and in the most severe forms by structural changes in certain brain regions. ${ }^{6364}$ Thus pathological stress can not only activate, but also fundamentally change, the responsiveness and output of the central stress circuits. These alterations could affect the individual output pathways of the general stress response differentially and in different directions; for example, increase or decrease in target specific sympathetic outputs, increase or decrease in certain vagal outputs, up or downregulation of the HPA axis, and up or downregulation of pain perception. Some of the best characterised alterations in this central adaptation to pathological stress are an increase in CRF synthesis and secretion, ${ }^{65}{ }^{66} 67$ an increase in the activity and sensitivity of central noradrenergic systems, ${ }^{3168-71}$ and either downregulation or sensitisation of GC receptors and adrenocorticotropic hormone release. ${ }^{72}$ As a consequence of these alterations in the central stress circuitry, secondary changes in receptor systems can occur in spinal ${ }^{73}$ or peripheral target cells of the output systems. ${ }^{74}$ Thus in cases of pathological stress resulting in permanent changes in the central stress circuitry, life long changes in peripheral receptor systems may also be expected. Finally, changes in mood and affect associated with alterations in the stress response have been reported. ${ }^{32} 75$

\section{AUTONOMIC RESPONSE}

The classical description of the autonomic nervous system to stress in the context of the "fight and flight" response by Cannon ${ }^{76}$ has focused on the stereotypic and global activation of the sympathetic nervous system. However, despite the integrated nature of the response to different stressors, there is considerable variability in the specifics of the peripheral output. At the level of the PVN of the hypothalamus, the cells that give rise to major classes of visceromotor projections are separate from another, suggesting they are not necessarily called into play in a stereotyped all or none matter, but rather that the potential exists for differential recruitment. ${ }^{77}$ In the periphery, 12 different functional groups of sympathetic neurones have been identified. $^{78}$ Some of these pathways regulate mucin production by large intestinal goblet cells, net water absorption by intestinal epithelial cells, ${ }^{79}$ mucosal permeability, ${ }^{80}$ mast cell degranulation, ${ }^{82}$ and possibly release of peptides from enterochromaffin cells.

Importantly, some of the sympathetic pathways have a direct immunomodulatory function. ${ }^{83}$ Evidence has been provided to suggest that there is a functionally distinct branch of the sympathetic nervous system dedicated specifically to immune modulation. ${ }^{78}$ Noradrenergic sympathetic nerve fibres innervate the vasculature and parenchyma of lymphoid organs, including the gut. ${ }^{84}$ These nerves and their principal neurotransmitter noradrenaline can influence (a) basic immune cell function such as proliferation, differentiation, cell trafficking, and cytokine production; (b) acquired immune responses, and (c) autoimmune reactivity in susceptible strains. ${ }^{83}$ For example, activation of the sympathetic system causes systemic secretion of IL- 6 from immune cells. IL- 6 , by inhibiting TNF- $\alpha$ and IL-1 $\beta$, and by activating the HPA axis, participates in the stress induced suppression of the immuneinflammatory reactions. ${ }^{85}$ The effects of the sympathetic system on immune cell function are consistent with the reported suppressing effect of naturalistic and certain experimental induced stressors on immune function. ${ }^{86}$ However, in experimentally induced urethral inflammation, ${ }^{87}$ arthritis, ${ }^{88}$ and colitis ${ }^{89}$ in rats, sympathectomy has been shown to reduce inflammation.
Stress related increases in plasma adrenaline (and GCs) play an important role in the facilitation of memory in amygdala-hippocampal circuits, including the development of conditioned fear. ${ }^{90}$ Adrenaline stimulated vagal feedback has also been implicated in the activation of endogenous pain modulation circuits. ${ }^{91}$

In addition to activation of sympathetic pathways, various acute stressors produce a characteristic biphasic pattern of parasympathetic activation, consisting of gastrovagal inhibition and activation of sacral parasympathetic output. ${ }^{92}$ Similar to the different subclasses of central sympathetic neurones, subpopulations of function and target specific vagal motor neurones have been identified. Pathological stress has also been associated with persistent decreases in cardiovagal tone and in cardiovagal responsiveness to stress. ${ }^{93} 94$

Viewed together, these results demonstrate that the interface between the gut lumen and neural, endocrine, and immune pathways is under close control of the autonomic nervous system. Alterations in the autonomic regulation of this interface, under conditions of allostatic load, are likely to play an important role in the modulation of secretion, motility, inflammation, and sensory response of the gut to luminal contents.

HYPOTHALAMIC-PITUITARY-ADRENAL (HPA) AXIS

The HPA axis is acutely activated by both interoceptive ${ }^{34} 53$ and exteroceptive stressors. ${ }^{75}$ The peripheral GC response to stress, in parallel with the sympathetic response plays a prominent role in suppression of the inflammatory response. In addition, a central mechanism in the normal counterregulation of stress induced HPA axis activation is GC mediated feedback by GC receptors in certain brain regions such as the hippocampus and medial prefrontal cortex (see fig 1). ${ }^{95} 96$ This feedback mechanism observed in response to acute stress can be up or downregulated in various chronic disease states. Hyperactivity of the HPA axis manifesting as hypercortisolism as seen in certain forms of depression has been considered the classical form of a generalised stress response which has escaped its usual counterregulation. ${ }^{75}$ Such hyperactivity has also been reported in anorexia nervosa, ${ }^{97}$ panic disorder, ${ }^{98}$ and sexual abuse. ${ }^{41} \mathrm{~A}$ decrease in GC receptor expression has been observed in animal models of chronic stress ${ }^{99}$ and in adult animals exposed to perinatal stress. ${ }^{31} \mathrm{~A}$ decrease in central GC receptors may be secondary to reversible downregulation of the receptor or permanent destruction of GC containing brain regions. ${ }^{63} 100101$

A different pattern of stress induced HPA dysregulation has been described in patients with post-traumatic stress disorder ${ }^{72}$ chronic fatigue syndrome, ${ }^{102}$ fibromyalgia, ${ }^{103}$ and possibly diarrhoea predominant IBS. ${ }^{104}$ Published reports suggest that these patient populations have evidence of a highly sensitised HPA axis characterised by decreased basal cortisol levels, increased number of lymphocyte GC receptors, greater suppression of cortisol to dexamethasone, and a more sensitised pituitary gland. ${ }^{72}$ Thus in addition to the classic pattern of increased cortisol levels in response to acute stress, there appears to be a pattern characterised by diminished cortisol levels as a result of a stronger negative feedback inhibition in certain types of disorders associated with pathological stress. This diminished cortisol response may be associated with increased central CRF responses to stress. ${ }^{65}$ On the other hand, decreased corticosterone response to stress has been reported in chronically stressed rats, associated with decreased expression of CRF mRNA in the PVN. ${ }^{105}$ The different patterns of HPA axis dysregulation may be related 
to genetic factors and/or develop in response to different types of pathological stress (for example, chronicity, severity).

In summary, HPA axis responses vary in different disease states with different impacts on duration of the stress response and on peripheral and central cortisol levels. Chronically elevated cortisol levels can be associated with structural irreversible changes in certain brain regions.

\section{MODULATION OF GUT IMMUNE FUNCTION}

Peripheral outputs of the stress response, in particular GCs and catecholamines, have profound effects on cytokine networks, including those in the gut mucosa. ${ }^{105 a}$ Via its peripheral mediators, stress influences the production of key regulatory type 1 and type 2 cytokines, T helper (Th) 1 and Th2 functions, and components of cellular and humoral immunity. In the healthy organism, both GCs and catecholamines suppress Th1 responses and cellular immunity and shift the immune response towards Th2 responses and humoral immunity. In contrast, in Crohn's disease, the response pattern is shifted towards Th1 responses. ${ }^{105 \mathrm{~b}}$ Based on these observations, one might speculate that the different patterns of the stress response in chronic functional and inflammatory conditions of the gut (see below) may have opposite effects on the Th1/Th2 balance in the gut mucosa.

MODULATION OF VISCEROSOMATIC SENSITIVITY

Both clinical and animal experimental data strongly support the concept of stress and fear induced analgesia resulting in decreased somatic pain perception. ${ }^{106}{ }^{107}$ Stress induced analgesia is mediated by descending pain inhibitory pathways and, depending on the nature and severity of the stressor, is partially mediated by opioidergic, glutaminergic, and serotonergic systems. ${ }^{108}$ Recent evidence suggests that this stress induced somatic hypoalgesia can be accompanied by a stress induced visceral hyperalgesia. ${ }^{109110}$ One way to explain these observations is the concept that both pain facilitatory and inhibitory systems are activated simultaneously in response to stress, the net effect being determined by the relative contribution of these opposing influences. ${ }^{111}$ Another hypothesis assumes that the visceral hyperalgesia is indirectly mediated by a population of sympathetic and/or parasympathetic nerves, stimulating the release of chemicals from cells within the gut wall (for example, mast cells, ${ }^{112}$ enterochromaffin cells) with sensitising effect on visceral afferent terminals. ${ }^{12}$ The role of pathological stress on the relative activation of this dual activation has not been characterised.

In summary, stress is associated with modulation of visceral and somatic sensitivity. Alterations in these endogenous stress activated pain modulation systems may play an important role in several functional visceral or somatic syndromes characterised by chronic discomfort and pain.

\section{MONOAMINERGIC SYSTEMS}

Noradrenergic, serotonergic, and cholinergic projection neurones to cortical (prefrontal cortex) and subcortical (including PVN, amygdala, hippocampus, nucleus tractus solitarius) regions play an important role in emotional arousal and in feedback modulation of the emotional motor system. Evidence for reciprocal positive feedback regulation of hypothalamic CRF neurones and noradrenergic locus coeruleus neurones has been reported. ${ }^{54113}$ For example, upregulation of tyrosine hydroxylase in locus coeruleus neurones has been reported in perinatally stressed rats which show upregulation of hypothalamic $\mathrm{CRH},{ }^{31}$ and parallel downregulation of message for $\mathrm{CRH}$ and tyrosine hydroxylase has been demonstrated during long term treatment of rats with imipramine. ${ }^{34}$ For example, noradrenergic modulation of synaptic vagal transmission in the nucleus tractus solitarius can be assumed to play a role in the modulation of vagovagal reflexes, ${ }^{62114115}$ including those regulating gastric accommodation, regulation of spontaneous transient lower oesophageal sphincter relaxation, and duodenogastric reflexes. Chronic overactivity of these systems, as observed in certain animal models of social stress ${ }^{62}$ and in patients with post-traumatic stress syndrome ${ }^{68}$ has been shown to be associated with downregulation of autoreceptors $\left(\alpha_{2}\right.$, $5-\mathrm{HT}_{1 \mathrm{~A}}$ receptors ${ }^{62} 116$ resulting in enhanced release of noradrenaline and serotonin, respectively. Enhanced release in turn may result in downregulation of postsynaptic receptors (such as $\beta$ adrenergic and $\alpha_{1}$ receptors). ${ }^{62117}$ These neuroplastic changes would initially increase noradrenaline release (presynaptic) but ultimately decrease activation of postsynaptic target neurones. In addition, excessive release of transmitter could result in depletion of noradrenaline and serotonin further decreasing postsynaptic neurone activation. The time course and extent of these adaptive changes to chronic stress differ between involved brain regions. ${ }^{62} 116$ Thus similar to alterations in the GC mediated system, neuroplastic alterations in aminergic systems may play a prominent role in the chronic biasing of the stress response towards maladaptive responses.

In summary, central aminergic networks involving serotonergic, noradrenergic, and cholinergic pathways play an important role in mediating the output of the central stress response both to specific regions of the brain (arousal, emotion) and to the periphery (autonomic, pain modulation). Alterations in the gain and effectiveness of these networks are likely to play a central role in the wide range of maladaptive responses to pathological stress, manifesting as both affective and somatic disorders.

\section{Possible role of allostasis in chronic gastrointestinal disorders}

The association of disease activity with certain types of stressors in FGD, IBD, and probably GORD suggests that the alterations in specific outputs of the central stress circuits, as well as the adaptive changes in peripheral target cells induced by pathological stress and facilitated by genetic factors, play a pathophysiological role in disease activity. While such altered outputs may be solely responsible for predominant symptoms in IBS and possibly functional dyspepsia, they may only play a modulatory role in the other disorders. It is important to realise that fear conditioning and interoceptive conditioning ${ }^{118}$ are likely to play important roles in triggering stress responses to situations and contexts which by themselves are not threatening or stressful. ${ }^{119}$ Below we will summarise selected reports of altered autonomic, neuroendocrine, and endogenous sensory modulation in FGD, IBD, and GORD, viewing these alterations as changes not in isolation but as alterations in the integrated response to stressors as described in fig 1 .

\section{Functional gastrointestinal disorders}

\section{CHANGES IN AUTONOMIC NERVOUS SYSTEM RESPONSES}

In both healthy humans and animals, stressors have been shown to result in a characteristic stress induced slowing of gastric emptying, ${ }^{120}$ increase in distal colonic motility, ${ }^{121} 122$ and acceleration of intestinal transit. ${ }^{92}{ }^{123}$ In the most common functional gastrointestinal disorders, IBS and FD, persistent alterations of autonomic responsiveness is likely to play a role in altered bowel habits and alteration in gastric emptying, respectively. Evidence for such alterations in IBS includes increased responses of distal colonic motility in response to laboratory stress ${ }^{121}$ and possibly food 
intake $^{124}$ and delayed gastric emptying in a subset of patients. $^{125}$

A model of IBS, taking into account altered autonomic regulation of gastric and distal colonic function and based on upregulation of CRF containing neurones in Barrington's nucleus (part of the locus coeruleus complex) has recently been reported by Valentino and coworkers. ${ }^{52}$ While descending CRF containing projections from this pontine nucleus to the distal colon may mediate increased stress and food induced motor responses of the distal colon, ascending projections to the locus coeruleus and to the forebrain may be responsible for mediating arousal and shifting attention to visceral afferent stimuli. Increased expression and release of CRF in IBS patients, or a subset of patients, are also consistent with the reported evidence for increased sympathetic responses. ${ }^{104}$ 126-128

Changes in the frequency of high amplitude propagated contraction in the colon, presumably via alteration in vagal colonic regulation, may play an important role in diarrhoea and slow transit constipation, thereby determining the predominant bowel habit pattern in IBS. ${ }^{129-131}$ In FD, reported findings of delayed gastric emptying, decreased antral motor activity to food and stress, ${ }^{120}{ }^{132}$ and impaired proximal gastric accommodation to a meal ${ }^{133}$ and to duodenal distension ${ }^{134}$ are also consistent with an alteration in the gain of vago-vagal reflexes, possibly by central monaminergic systems, as discussed above.

There is evidence that decreased cardiovagal tone is present in certain patients with functional dyspepsia ${ }^{135} 136$ and in subsets of patients with IBS. ${ }^{136}{ }^{137}$ Recent evidence from patients with functional constipation suggests that despite the heterogeneity of vagal motor neurones, changes in cardiovagal tone, vagal regulation of intestinal transit, and vagal regulation of colonic mucosal blood flow may all be reduced in parallel. ${ }^{138}$

\section{HPA AXIS CHANGES}

Evidence for alterations in HPA axis function has been demonstrated in diarrhoea predominant IBS patients who showed decreased 24 hour plasma cortisol, blunted cortisol responses, and normal adrenocorticotropic hormone responses to noxious rectosigmoid distension. ${ }^{104}$ In contrast, Heitkemper et al reported that urine cortisol levels obtained immediately on rising were significantly higher in IBS women compared with control women. ${ }^{128}$ Even though a thorough characterisation of HPA axis responses in FGD patients has not been reported, these preliminary findings suggest the pattern of sensitised GC feedback also reported in victims of abuse, ${ }^{39}$ fibromyalgia, and chronic fatigue syndrome. ${ }^{139}$ There is significant overlap in the epidemiology of all of these conditions with IBS. ${ }^{10}{ }^{140-143}$ While it is currently not known if these HPA axis changes are an epiphenomenon or play a role in symptom generation and pathophysiology of these syndromes, one may speculate on their possible role in the observed findings in postinfectious IBS patients. The reported persistence of chronic inflammatory mucosal changes after eradication of the infectious organism, ${ }^{4}$ and increased intestinal permeability and hyperplasia of enterochromaffin cells ${ }^{144}$ are consistent with an inadequate physiological response to acute gut inflammation, in particular an inadequate cortisol (and possibly an altered sympathetic) response. One may speculate that a downregulated cortisol response to interoand exteroceptive stressors might also predispose IBS patients to chronic inflammatory conditions, such as asthma, rheumatoid arthritis, or IBD. ${ }^{145}$

CHANGES IN PAIN MODULATION

Suggestive evidence for alterations in stress induced modulation of viscerosomatic sensitivity comes from human and animal studies. IBS patients show cutaneous hypoalgesia ${ }^{146147}$ combined with visceral hypersensitivity, ${ }^{148}$ a similar pattern as seen in the rat in response to psychological stressors. ${ }^{110}$ Preliminary results using psychological laboratory stress in healthy volunteers suggests a stress induced increase in colonic or rectosigmoid sensitivity to distension. ${ }^{109}$ Even though all published human studies are open to methodological criticism, they are consistent with reported findings in animals of differential viscerosomatic pain modulation. It is of interest to note that patients with bulimia (who, in contrast with IBS patients have a hyperactive HPA axis) show cutaneous hypoalgesia also which precedes symptom exacerbation. ${ }^{149}$

CHANGES IN BRAIN ACTIVATION

Functional brain imaging studies of IBS patients have shown decreased activation of the perigenual cingulate and hippocampus. ${ }^{150}$ Decreased perigenual cingulate/medial prefrontal cortex activity has also been reported in patients with depression ${ }^{151}$ and with post-traumatic stress disorder. ${ }^{152}$ Bremner et al reported a decrease in prefrontal and orbitofrontal cortical metabolism in patients with posttraumatic stress disorder in response to the $\alpha_{2}$ antagonist yohimbine. ${ }^{6}{ }^{2}$ Together with results from preclinical studies showing decreased metabolism in cortical regions with high noradrenaline release, ${ }^{153}$ these results are consistent with enhanced noradrenaline release in these brain regions in patients with post-traumatic stress disorder. One may speculate that the decreased activation in the perigenual cortex and other brain regions seen in IBS patients may also be related to exaggerated noradrenaline release in response to stress.

In summary, IBS patients, in particular the nonconstipated subpopulation, present with a pattern consistent with enhanced stress responsiveness manifested by predicted autonomic and pain modulatory responses, and sensitised GC feedback. This response pattern is associated with changes in brain activity in response to stress consistent with increased central noradrenaline release. The blunting of the HPA axis may precede the onset of IBS symptoms and may predispose individuals to develop post-infectious IBS. The fact that up to $40 \%$ of IBS patients show evidence of increased anxiety, ${ }^{154}$ and the fact that the changes are similar to those reported in a variety of other so called "functional" disorders, suggest a top down model, in which the alterations in the central stress circuits in predisposed individuals are triggered by pathological exteroceptive stressors and play a primary role in pathophysiology.

\section{Inflammatory bowel disease}

CHANGES IN AUTONOMIC NERVOUS SYSTEM RESPONSES

Little is known about specific alterations in the autonomic nervous system responses to interoceptive or exteroceptive stressors in patients with IBD or in animal models of colitis. However, several animal studies provide indirect evidence for involvement of autonomic dysregulation.

Qiu and colleagues ${ }^{155}$ recently provided evidence that short term moderate stress can enhance the response of the colon to chemically induced inflammation. Their findings are consistent with a model in which the effect of the stressor is primarily mediated by autonomic responses, and not by stress induced alterations in neuroendocrine function (HPA axis). The authors show that $\mathrm{CD}^{+}$cells which are sensitised by a chemically induced colitis can be reactivated by a subthreshold dose of the same chemical irritant applied to the colon six weeks after the initial insult, at a time of complete mucosal healing. They provide evidence that this effect requires sensitised $\mathrm{CD} 4^{+}$lymphocytes, and is mediated in part by an effect of the stressor on mucin 
production and colon permeability, presumably facilitating access of the irritant to the sensitised lymphocytes. A previous study by the same group in the trinitrobenezene sulphonic acid rat model had demonstrated stress induced increases in myeloperoxidase levels in the rat colon, six weeks after induction of colitis. ${ }^{156}$ A series of articles from Perdue's group provided evidence for stress induced increases in mucosal permeability of the rat intestine. ${ }^{8182} 157$ Pharmacological evidence for mediation of these permeability changes by cholinergic and adrenergic nerves, mast cell degranulation, and involvement of peripheral CRH has been provided. ${ }^{81}$ The source of peripheral CRF in these stress mediated changes is not known but may include immune cells, postganglionic sympathetic neurones, and colonic enterochromaffin cells. In this context, it is of interest that increased intestinal permeability has also been reported in certain patients with post-infectious IBS symptoms. ${ }^{144}$

Taken together, these findings in animals together with the extensive literature on immune modulation by the sympathetic nervous system indirectly support a role for stress mediated activation of certain sympathetic (in addition to parasympathetic) nerves in increasing the permeability of the gut, altering the quantity of mucin, and altering immune function in the reactivation of inflammatory mucosal changes in chronic colitis. As activation of sympathetic nerve pathways during acute stress is generally associated with an immunosuppressive role, alterations in stress activated autonomic output, possibly associated with altered cortisol responses, must be responsible for a maladaptive response.

CHANGES IN HPA AXIS RESPONSES

Little is known about HPA axis regulation in patients with IBD. One may speculate that similar to patients with rheumatoid arthritis, ${ }^{36}$ HPA axis responses are downregulated by the chronic colonic inflammation in IBD patients, thereby compromising the organism's ability to counterregulate mucosal inflammation. ${ }^{158}$ Preliminary studies in rats with TNB induced colitis are indeed consistent with such downregulation (Tache, personal communication, 1999). Furthermore, in analogy to findings in Fisher and Lewis rats $^{34}$ there may be genetic factors, such as a hyporesponsive HPA axis in subsets of IBD patients, that predispose to the persistence of inflammation. Evidence for such greater susceptibility of CRF hyposecreting Lewis rats to stress induced colitis has recently been provided. ${ }^{92}$ However, no evidence for a role of alterations in stress induced HPA axis activation has been found between rodents with short term colitis that showed stress induced recurrence of mucosal changes and those that did not. ${ }^{155156159160}$ As only single time point measurements of corticosterone responses to stress were reported in these studies, it is not known if diurnal variation or 24 hour corticosterone output was altered in these animals.

In summary, one can only speculate that IBD patients may show similar downregulation of the HPA axis as patients with rheumatoid arthritis. However, in contrast with IBS, fibromyalgia, or post-traumatic stress disorder patients where this blunting appears to be related to increased central CRH release combined with enhanced GC receptor mediated feedback, HPA axis downregulation is likely to be secondary to decreased CRH gene expression and secretion.

\section{CHANGES IN PAIN MODULATION}

The limited information on visceral and somatic pain perception in patients with IBD suggests that acute inflammatory changes (at the site of distension) are associated with enhanced visceral sensitivity, ${ }^{161}$ while patients in remission have normal perception of rectal distension. ${ }^{162}$ Patients with Crohn's disease of the small bowel show normal or decreased sensitivity to rectal distension. ${ }^{163}$ In contrast, induction of colonic pain by repetitive sigmoid stimulation resulted in a decrease in rectal pain sensitivity, consistent with adequate activation of endogenous pain inhibitory pathways. ${ }^{164}$

\section{CHANGES IN BRAIN ACTIVATION}

Preliminary results comparing regional brain activation assessed by $\mathrm{O} 15$ water positron emission tomography between healthy control subjects, and patients with mild ulcerative colitis and IBS suggest similar activation patterns both during rectal distension as well as during anticipation of such distension, while IBS patients showed decreased activation of the perigenual cingulate, amygdala, and hippocampus. ${ }^{165}$

In summary, our understanding of the outputs of the central stress circuits in IBD is incomplete. However, it appears to be different from that observed in FGD patients. One may speculate that the output is comprised of downregulation of the HPA axis, alteration of gut targeted branches of the sympathetic nervous system, and normal activation of stress induced pain modulation pathways. In contrast with the pattern seen in IBS patients, the pattern in IBD may reflect genetic predisposition to a hyporeactive HPA axis combined with secondary downregulation in the central response to a chronic interoceptive stressor (for example, mucosal inflammation). In those IBD patients who appear to have comorbid IBS, the low cortisol response may be associated with alterations in autonomic and pain modulation seen in IBS patients.

\section{GORD}

Despite the suggestive epidemiological data on the association of GORD with stressful life events, little is known about possible alterations in the peripheral outputs of the central stress system in subgroups of patients with GORD. Recent evidence is consistent with a primary role of spontaneous transient relaxations of the lower oesophageal sphinter in the mediation of pathological acid reflux. ${ }^{166}$ One may speculate on the possible role of altered transmission of vago-vagal reflexes by central aminergic systems in this dysregulation (see above). Alteration of the gastrooesophageal high pressure zone by changes in diaphragmatic function may also contribute to stress induced symptom exacerbation. Changes in diaphragmatic function related to stress induced breathing patterns have been reported. ${ }^{167}$ In addition, slowing of gastric emptying by inhibition of vagal gastric regulation may contribute to stress induced symptoms. Finally, recent evidence suggests a role for endogenous pain modulation systems in stress induced increase in oesophageal chemosensitivity. ${ }^{168}$

In conclusion, recent breakthroughs in understanding the neurobiology of stress emphasise the importance of the peripheral outputs of the central stress response in the modulation of some of the most common gastrointestinal disorders. The same central alterations discussed above may also explain the association with affective disorders seen in a certain percentage of patients with functional gastrointestinal disorders, and the overlap with a variety of clinical syndromes such as fibromyalgia, chronic fatigue syndrome, and interstitial cystitis. Animal models of different pathological interoceptive and exteroceptive stressors $^{9} 3164169170$ are available and, together with knockout technology will help to determine which components of the altered stress response are epiphenomena and which play a primary role in the pathophysiology. Finally, a better understanding of the role of pathological stressors in modulation of disease activity will have important 
therapeutic implications. Both pharmacological interventions (for example, CRF1 antagonist) as well as educational-behavioural interventions in selected patient populations are likely to become an integral part of cost effective disease management of FGD, IBD, and GORD.

UCLA/CURE Neuroenteric Disease Program,

E A MAYER

UCLA Division of Digestive Diseases,

Los Angeles, CA 90024, USA

Correspondence to: GLA VA Healthcare System, 11301 Wilshire Boulevard, Building 115, Room 223, Los Angeles, California 90073, USA. emayer@ucla.edu

1 Drossman DA, Sandler RS, McKee DC. Bowel patterns among subjects not seeking health care. Gastroenterology 1982;83:529-34.

2 Whitehead WE, Crowell MD, Robinson JC, et al. Effects of stressful life events on bowel symptoms: subjects with irritable bowel syndrome compared with subjects without bowel dysfunction. Gut 1992;33:825-30.

Bennett EJ, Tennant CC, Piesse C, et al. Level of chronic life stress predicts clinical outcome in irritable bowel syndrome. Gut 1998;43:256-61.

4 Gwee KA. The role of psychological and biological factors in postinfective gut dysfunction. Gut 1999;44:400-6.

Greene B, Blanchard EB. Cognitive therapy for irritable bowel syndrome. $\mathcal{F}$ Consult Clin Psychol 1994;62:576-82.

6 Garrett VD, Brantley PJ, Jones GN, et al. The relationship between daily stress and Crohn's disease. F Behav Med 1991;14:87-96.

7 Duffy LC, Zielezny MA, Marshall JR, et al. Relevance of major stress events as an indicator of disease activity prevalence in inflammatory bowel disease. Behav Med 1991;17:101-10.

8 Fava GA, Pavan L. Large bowel disorders. I. Illness configuration and life events. Psychother Psychosom 1976;27:93-9.

9 Stamm R, Akkermans LMA, Wiegant VM. Trauma and the gut: Interactions between stressful experience and intestinal function. Gut 1997;40:704-9.

10 Drossman DA, Leserman J, Nachman G, et al. Sexual and physical abuse in women with functional or organic gastrointestinal disorders. Ann Intern Med 1990;113:828-33.

11 Drossman DA, Talley NJ, Leserman J, et al. Sexual and physical abuse and gastrointestinal illness. Review and recommendations. Ann Intern Med 1995;123:782-94.

12 Walker EA, Katon WJ, Roy-Byrne PP, et al. Histories of sexual victimization in patients with irritable bowel syndrome or inflammatory bowel disease. Am $\mathcal{F}$ Psychiatry 1993;150:1502-6.

13 Talley NJ, Fett SL, Zinsmeister AR, et al. Gastrointestinal tract symptoms and self-reported abuse: a population-based study. Gastroenterology 1994;107:1040-9.

14 Scarinci IC, McDonald-Haile J, Bradley LA, et al. Altered pain perception and psychosocial features among women with gastrointestinal disorders and history of abuse: a preliminary model. Am F Med 1994;97:108-18.

15 Levenstein S, Ackerman S, Kiecolt-Glaser JK, et al. Stress and peptic ulcer disease. FAMA 1999;281:10-11.

16 Spicer CC, Stewart DN, Winser DMR. Perforated peptic ulcer during the period of heavy air raids. Lancet 1944;14.

17 Aoyama N, Kinoshita Y, Fujimoto S, et al. Peptic ulcers after the HanshinAwaji earthquake: increased incidence of bleeding gastric ulcers. Am f Gastroenterol 1998;93:311-16.

18 Pomakov P, Gueorgieva S, Stantcheva J, et al. Ulceres gastro-duodenaux pendant la periode d'une crise economique aigue. F Radiol 1993;74:265-7.

19 Lam SK, Hui WM, Shiu LP, et al. Society stress and peptic ulcer Lam SK, Hui WM, Shiu LP, et al. Society strot
perforation. $\mathcal{F}$ Gastroenterol Hepatol 1995;10:570-6.

20 Nice DS, Garland CF, Hilton SM, et al. Long-term health outcomes and medical effects of torture among US Navy prisoners of war in Vietnam. 7AMA 1996;276:375-81.

21 Levenstein S, Kaplan GA, Smith MW. Psychological predictors of peptic ulcer incidence in the Alameda County Study. $\mathcal{F}$ Clin Gastroenterol 1997;24: $140-6$.

22 Peterson WL, Graham DY. Helicobacter pylori In: Feldman M, Scharschmidt B, Sleisenger $\mathrm{MH}$, eds. Gastrointestinal and liver disease: pathophysiology, diagnosis, management, 6 edn. Philadelphia: WB Saunders, 1997:604-19.

23 A Gallup survey on heartburn across America. Princeton, NJ, 1988.

24 Bradley LA, Richter JE, Pulliam TJ, et al. The relationship between stress and symptoms of gastroesophageal reflux: the influence of psychological factors. Am $\mathcal{F}$ Gastroenterol 1993;88:11-9.

25 Selye H. Stress. Quebec: Acta Medical Publisher, 1950

26 Chrousos GP, Gold PW. The concepts of stress and stress system disorders: overview of physical and behavioral homeostasis. $\mathscr{f} A M A$ 1992;267:124452.

27 Chrousos GP, Loriaux DL, Gold PW. The concept of stress and its historical development. Adv Exp Med Biol 1988;245:3-7.

8 Sawchenko PE, Li H-Y. Circuits and mechanisms governing hypothalamic responses to stress: a tale of two paradigms. In: Ericsson A, Mayer EA, Saper CB, et al, eds. The biological basis for mind body interactions, vol. 6, 122 edn. Amsterdam: Elsevier Science, 2000:59-75.

29 Sterling P, Eyer J, Fisher S, et al, eds. Handbook of life stress, cognition and health. New York: John Wiley, 1988:629-49.

30 Eley TC, Plomin R. Genetic analysis of emotionality. Curr Opin Neurobiol 1997;7:279-84

31 Ladd CO, Huot RL, Thrivikraman KV, et al. Long-term behavioral and neuroendocrine adaptations to adverse early experience. In: Mayer EA, Saper CB, eds. The biological basis for mind body interactions, vol. 7, 122 edn. Amsterdam: Elsevier, 2000:79-101.

$32 \mathrm{McEwen}$ BS. Protective and damaging effects of stress mediators. N Engl $\mathcal{F}$ Med 1998;338:171-9.

33 Perlstein RS, Whitnall MH, Abrams JS, et al. Synergistic roles of interleukin-6, interleukin-1, and tumor necrosis factor in adrenocorticotro-
pin response to bacterial lipopolysaccharide in vivo. Endocrinology 1993;132:946-52.
34 Sternberg EM, Chrousos GP, Gold PW. The stress response and the regulation of inflammatory disease. Ann Intern Med 1992;117:854-66.

35 Turnbull AV, Rivier CL. Regulation of the hypothalamic-pituitary-adrenal axis by cytokines: actions and mechanisms of action. Physiol Rev 1999;79:

36 Neeck G, Federlin K, Graef V, et al Adrenal secretion of cortisol in patients with rheumatoid arthritis. F Rheumatol 1990;17:24-9.

37 Sternberg EM. Neuroendocrine hormonal factors in rheumatoid arthritis and related conditions. Curr Opin Rheumatol 1990;2:436-40.

38 Sternberg EM. Interactions between the immune and neuroendocrine systems. In: Mayer EA, Saper CB, eds. The biological basis for mind body interactions, vol. 4, 122 edn. Amsterdam: Elsevier Science, 2000:35-42.

39 Heim C, Newport DJ, Heit S, et al. Pituitary-adrenal responses to CRF stimulation in adult survivors of childh

sion. Soc Neurosci Abstr 1999;25:1454.

40 Bremner JD, Narayan M, McGlashan J, et al. Lasting effects of early childhood sexual abuse on the hypothalamic-pituitary-adrenal axis. Soc Neurosci Abstr 1999;25:1454.

41 DeBellis M, Chrousos GP, Dorn LD, et al. Hypothalamic-pituitary-adrenal axis dysregulation in sexually abused girls. F Clin Endocrinol Metab

42 Diagnostic and Statistical Manual of Mental Disorders, 4 edn. Washington, DC: American Psychiatric Association, 1994:393-444.

43 Stamm R, Yehuda R, Giller EL Jr, et al. Hypothalamic-pituitary-adrenal functioning in post-traumatic stress disorder: expanding the concept of the stress response spectrum In: Friedman MJ, Charney DS, Deutch AY, eds. Neurobiological and clinical consequences of stress. Philadelphia: LippincottRaven, 1995:351-66.

44 Taylor SE. Adjusting to threatening events: A theory of cognitive adaptation. Am Psychol 1983;41:1161-73.

45 Henry JP, Stephens PM. Stress, health, and the social environment: a sociobiologic approach to medicine. New York: Springer, 1977.

46 LeDoux JE. The emotional brain: the mysterious underpinnings of emotional life. New York: Simon and Schuster, 1996.

47 Dantzer R. Stress, personal control, and health. New York: John Wiley and Sons, 1989:277-94.

48 Craske MG. Anxiety disorders: psychological approaches to theory and treatment. Boulder: Westview Press/Perseus Book, 1999

49 Bandler R, Price JL, Keay KA, et al, eds. The biological basis for mind body interactions, vol. 24, 122 edn. Amsterdam: Elsevier Science, 2000:332-47.

50 Vogt BA, Sikes RW, Vogt LJ, et al, eds. Neurobiology of cingulate cortex and limbic thalamus: a comprehensive handbook, vol. 10. Boston: Birkhaeuser, 1993:313-44

51 Holstege G, Bandler R, Saper CB, eds. The emotional motor system. Progress in brain research. Amsterdam: Elsevier, 1996:29.

52 Valentino RJ, Miselis RR, Pavcovich LA. Pontine regulation of pelvic viscera: pharmacological target for pelvic visceral dysfunction. Trends Pharmacol Sci 1999;20:253-60.

53 Chrousos GP. The hypothalamic-pituitary-adrenal axis and immunemediated inflammation. N Engl f Med 1995;332:1351-62.

54 Plotsky PM, Cunningham ET, Widmaier EP. Catecholaminergic modulation of corticotropin-releasing factor and dexamethasone secretion. Endocrinol Rev 1989;10:437-58.

55 Tache Y, Moennikes H. Mayer EA, et al, eds. Basic and clinical aspects of chronic abdominal pain, vol. 12. Amsterdam: Elsevier, 1993:142-51.

56 Tache Y, Martinez V, Million M, et al. Corticotropin-releasing factor and the brain-gut motor response to stress. Can $\mathcal{F}$ Gastroenterol 1999;13(suppl A): $18-25 \mathrm{~A}$.

57 Tache Y, Monnikes H, Bonaz B, et al. Role of CRF in stress-related alterations of gastric and colonic motor function. Ann N Y Acad Sci 1993;697:233-63.

58 Timpl P, Spanagel R, Sillaber I, et al. Impaired stress response and reduced anxiety in mice lacking a functional corticotropin-releasing hormone receptor. Nat Genet 1998;19:162-6.

59 Smith GW, Aubry JM, Dellu F, et al. Corticotropin releasing factor receptor 1-deficient mice display decreased anxiety, impaired stress response, and aberrant neuroendocrine development. Neuron 1998;20:1093-102.

60 Glowa JR, Sternberg EM, Gold PW. Differential behavioral response in LEW/N and F344/N rats: effects of corticotropin releasing hormone. Prog Neuropsychopharmacol Biol Psychiatry 1992;16:549-60.

61 Fuchs E, Fluegge G. Modulation of binding sites for corticotropin-releasing hormone by chronic psychocial stess. Psychoneuroendocrinology 1995;20:3351

62 Fluegge G. Alterations in the central nervous alpha 2-adrenoceptor system under chronic psychosocial stess. Neuroscience 1996;75:187-96.

63 Bremner JD, Randall P, Vermetten E, et al. Magnetic resonance imaging-based measurement of hippocampal volume in posttraumatic stress disorders related to childhood physical and emotional abuse-a preliminary report. Biol Psychiatry 1997;41:23-32.

64 Fuchs E, Uno H, Fluegge G. Chronic psychosocial stress induces morphological alterantion in hippocampal pyramidal neurons of the tree shrew. Brain Res 1995;673:275-82.

65 Bremner JD, Licinio J, Darnell A, et al. Elevated CSF corticotropin releasing factor concentrations in posttraumatic stress disorder. Am $\mathcal{F}$ Psychiatry 1997; 154:624-9.

66 Imaki T, Nahan JL, Sawchenko PE, et al. Differential regulation of corticotropin-releasing factor mRNA in rat brain regions by glucocorticoids and stress. $\mathcal{F}$ Neurosci 1991;11:585-99.

67 Owens MJ, Nemeroff CB. The role of corticotropin-releasing factor in the pathophysiology of affective and anxiety disorders: laboratory and clinical studies. Ciba Found Symp 1993;172:296-316.

68 Bremner JD, Innis RB, Ng CK, et al. Positron emission tomography measurement of cerebral metabolic correlates of yohimbine administration in combat related posttraumatic stress disorder. Arch Gen Psychiatry 1997; 54:246-54.

69 Reche AJ, Buffington CAT. Increased tyrosine hydroxylase immunoreactivity in the locus

70 Curtis AL, Pavcovich LA, Valentino RJ. Previous stress alters corticotropinreleasing factor neurotransmission in the locus coeruleus. Neuroscience 1995;65:541-50.

71 Curtis AL, Pavcovich LA, Valentino RJ. Long-term regulation of locus coeruleus sensitivity to corticotropin-releasing factor by swim stress. $\mathcal{F}$ Pharmacol Exp Ther 1999;289:1211-9. 
72 Yehuda R, Giller EL, Levengood RA, et al. Hypothalamic-pituitary-adrenal functioning in post-traumatic stress disorder: Expanding the concept of the
stress response spectrum. In: Friedman MJ, Charney DS, Deutch AY, eds. stress response spectrum. In: Friedman MJ, Charney DS, Deutch AY, eds.
Neurobiological and clinical consequences of stress: from normal adaptation to Neurobiological and clinical consequences of stress: from normal ada
PTSD, vol. 19. Philadelphia: Lippincott-Raven, 1995:351-65.

73 Pertovaara A. Antinociception induced by alpha-2-adrenoceptor agonists, with special emphasis on medetomidine studies. Prog Neurobiol 1993;40: 691-709.

74 Yehuda R, Boisonaeau D, Mason JW, et al. Relationship between lymphocyte glucocorticoid receptor number and urinary free cortisol excretion in mood, anxiety, and psychotic disorders. Biol Psychiatry excretion in mo

75 Gold PW, Goodwin FK, Chrousos GP. Clinical and biochemical manifestations of depression: relationship to the neurobiology of stress (parts 1 and 2). N Engl f Med 1988;319:348-53.

76 Cannon WB. Organization for physiological homeostasis. Physiol Rev 1929; 9:399-431.

77 Swanson LW, Kuypers HGJM. The paraventricular nucleus of the hypothalamus: cytoarchitectonic subdivisions and organization of projections to the pituitary, dorsal vagal complex, and spinal cord as demonstrated by retrograde fluorescence double-labeling methods. f Comp Neurol 1980;194:555-70.

78 Jaenig W, Habler H-J. Mayer EA, et al, eds. The biological basis for mind body interactions, 122 edn. Amsterdam: Elsevier Science, 2000:349-65.

79 Furness JB, Costa M, eds. The enteric nervous system, vol. 9. New York: Churchill Livingstone, 1987:207-38.

80 Lange S, Delbro DS. Adrenoceptor-mediated modulation of Evans blue dye permeation of rat small intestine. Dig Dis Sci 1995;40:2623-9.

81 Santos J, Saunders PR, Hanssen NP, et al. Corticotropin-releasing hormone mimics stress-induced colonic epithelial pathophysiology in the rat. $A m \mathcal{F}$ Physiol 1999;277:G391-3

82 Berin MC, Perdue MH. Effect of psychoneural factors on intestinal epithelial function. Can f Gastroenterol 1997;11:353-7.

83 Felten DL, Mayer EA, Saper CB, eds. The biological basis for mind body interactions, vol. 27, 122 edn. Elsevier Science, 2000:379-87.

84 Felten SY, Felten DL, Ader R, et al, eds. Psychoneuroimmunology, 2 edn. San Diego: Academic Press, 1991:27-69.

85 Peristein RS, Whitmall MH, Abrams JS, et al. Syndergistic roles of interleukin-6, interleukin- 1 and tumor necrosis factor in adrenocorticotropin response to bacterial lipopolysaccharide in vitro. Endocrinology 1993;132:946-52.

86 Kemeny ME, Gruenwald TL, Mayer EA, et al, eds. The biological basis for mind body interactions, vol. 21, 122 edn. Amsterdam: Elsevier Science, 2000: 289-306.

87 Nordling L, Liedberg H, Ekman P, et al. Influence of the nervous system on experimentally induced urethral inflammation. Neurosci Lett 1990;115: 183-8.

88 Levine JD, Dardick SJ, Roizen MF, et al. Contribution of sensory afferents and sympathetic efferents to joint injury in experimental arthritis. $\mathcal{F}$ Neurosci 1986;6:3423-9.

89 McCafferty DM, Wallace JL, Sharkey KA. Effects of chemical sympathectomy and sensory nerve ablation on experimental colitis in the rat. $A m \mathcal{F}$ Physiol 1997;272:G272-80.

90 Cahill L, Prins B, Weber M, et al. $\beta$-Adrenergic activation and memory for emotional events. Nature 1994;371:702-4.

91 Fillingim RB, Maixner W. Gender differences in the responses to noxious stimuli. Pain Forum 1995;4:209-21.

92 Martinez V, Rivier J, Tache Y. Central injection of a new corticotropinreleasing factor (CRF) antagonist, astressin, blocks CRF- and stress-related alterations of gastric and colonic motor function. I Pharmacol Exp Ther alterations of gastric

93 Verrier RL, Mittleman MA, Mayer EA, et al, eds. The biological basis for mind body interactions, vol 26, $122 \mathrm{edn}$. Amsterdam: Elsevier Science, 2000:36778

94 Musselman D, Nemeroff CB, Mayer EA, et al, eds. The biological basis for mind body interactions, vol. 5, 122 edn. Amsterdam: Elsevier Science, 2000: 43-58.

95 McEwen BS, Friedman JM, Charney DS, et al, eds. Neurobiological and clinical consequences of stress: from normal adaptation to PTSD. Philadelphia: Lippincott-Raven, 1995:135-50.

96 Sapolsky RM, Krey LC, McEwen BS. Glucocorticoid-sensitive hippocampal neurons are involved in terminating the adrenocortical stress response. Proc Natl Acad Sci USA 1984;81:6174-7.

97 Gold PW, Gwirtsman H, Avgerinos P, et al. Abnormal hypothalamicpituitary-adrenal function in anorexia nervosa; pathophysiological mechanisms in underwei

98 Gold PW, Pigot TA, Kling MK, et al. Basic and clinical studies with corticotropin releasing hormone: implications for a possible role in panic disorder. Psychiatr Clin North Am 1988;11:327-34.

99 Jacobson L, Sapolsky R. The role of the hippocampus in feedback regulation of the hypothalamic-pituitary-adrenocortical axis. Endocrinol Rev 1991;12: $118-34$

100 Bremner JD, Randall P, Scott TM, et al. MRI-based measurement of hippocampal volume in patients with combat-related posttraumatic stress disorder. Am f Psychiatry 1995;152:973-81.

101 McEwen BS, Mayer EA, Saper CB, eds. The biological basis for mind body interactions, 122 edn. Amsterdam: Elsevier, 2000

102 Sternberg EM. Hyperimmune fatigue syndromes: diseases of the stress response? f Rheumatol 1993;20:418-21 (published erratum appears in $\mathcal{f}$ Rheumatol 1993;20:925).

103 Crofford LJ, Pillemer SR, Kalogeras KT, et al. Hypothalamic-pituitaryadrenal axis perturbations in patients with fibromyalgia. Arthritis Rheum 1994;37:1583-92.

104 Munakata J, Mayer EA, Chang L, et al. Autonomic and neuroendocrine responses to recto-sigmoid stimulation. Gastroenterology 1998;114:808.

105 Albeck DS, McKittrick CR, Blanchard DC, et al. Chronic social stress alters levels of corticotropin-releasing factor and arginine vasopressin mRNA in rat brain. $\mathcal{f}$ Neurosci $1997 ; \mathbf{1 7}: 4895-903$.

105a Elenkov IJ, Chrousos GP. Stress hormones, Th1/Th2 patterns, pro/antiinflammatory cytokines and susceptibility to disease. Trend Endocrinol Metabol 1999;10:359-68. 105b Segal BM, Dwyer BK, Shevach EM. An interleukin (IL)-10/IL-12 immunoregulatory circuit controls susceptibility to autoimmune disease. $\mathcal{F}$ Exp Med 1998;187:537-46.

106 Basbaum AI, Fields HL. Endogenous pain control mechanisms: Review and hypothesis. Ann Neurol 1978;4:451-62.

107 Fanselow MS. Conditioned fear-induced opiate analgesia: a competing motivational state theory of stress analgesia. Ann $N$ Y Acad Sci $1986 ; 467: 40-54$.

108 Harris M, Feinmann C, Mason MK, et al, eds. Oral manifestations of systemic disease. Philadelphia: WB Saunders, 1990.

109 Delvaux MM. Stress and visceral perception. Can $\mathcal{f}$ Gastroenterol 1999;13(suppl A):32-6A.

110 Coutinho SV, Miller JC, Plotsky PM, et al. Effect of perinatal stress on responses to colorectal distension in adult rats. $\mathcal{F}$ Neurosci 1999;25:687.

111 Wei F, Dubner R, Ren K. Nucleus reticularis gigantocellularis and nucleus raphe magnus in the brain stem exert opposite effects on behavioral hyperalgesia and spinal Fos protein expression after peripheral inflammation. Pain 1999;80:127-41.

112 Gue M, Del Rio-Lacheze C, Eutamene H, et al. Stress-induced hypersensitivity to rectal distension in rats: role of CRF and mast cells. Neurogastroenterol Motil 1997;9:271-9.

113 Calogero AE, Chrousos GP, Gold PW. Catecholamine effects upon rat hypothalamic corticotropin-releasing hormone secretion in vitro. $\mathcal{F}$ Clin Invest 1988;82:839-46.

114 Fluegge G, Jurdzinski A, Brandt S, et al. Alpha 2-adrenergic binding sites in the medulla oblongata of tree shrees demonstrated by in vitro autoradiography: species related differences in comparison to the rat. $\mathcal{f}$ Comp Neurol 1990;297:253-66.

115 Flugge G, Johren O, Fuchs E. $\left[{ }^{3} \mathrm{H}\right]$ Rauwolscine binding sites in the brains of male tree shrews are related to social status. Brain Res 1992;597:131-7.

116 Fluegge G, Kramer M, Rensing S, et al. 5HT1A-receptors and behaviour under chronic stress: selective counteraction by testosterone. Eur $\mathcal{F}$ Neurosci 1998;10:2685-93.

117 Fluegge G, Ahrens O, Fuchs E. Beta-adrenoceptors in the tree shrew brain. II. Time-dependent effects of chronic psychosocial stress on $\left[{ }^{125} \mathrm{I}\right]$ iodocyanopindolol binding sites. Cell Mol Neurobiol 1997;17:417-32.

118 Razran G. The observable unconscious and the inferable conscious in current Soviet psychophysiology: Interoceptive conditioning, semantic conditioning, and the orienting reflex. Psychol Rev 1961;69:81-150.

119 Fendt M, Fanselow MS. The neuroanatomical and neurochemical basis of conditioned fear. Neurosci Biobehav Rev 1999;23:743-60.

120 Malagelada J-R. Tache Y, Wingate D, eds. Brain-gut interactions, vol 26. Boston: CRC Press, 1991:297-305.

121 Welgan $\mathrm{P}$, Meshkinpour H, Beeler M. The effect of anger on colon motor and myoelectric activity in irritable bowel syndrome. Gastroenterology 1988; 94:1150-6.

122 Welgan $\mathrm{P}$, Meshkinpour $\mathrm{H}$, Hoehler $\mathrm{F}$. The effect of stress on colon motor and electrical activity in irritable bowel syndrome. Psychosom Med 1985;47: 139-49.

123 Ditto B, Miller SB, Barr RG. A one-hour active coping stressor reduces small bowel transit time in healthy young adults. Psychosom Med 1998;60:7-10.

124 Niederau C, Faber S, Karaus M. Cholecystokinin's role in regulation of colonic motility in health and in irritable bowel syndrome. Gastroenterology 1992;102:1889-98.

125 Evans PR, Bak YT, Shuter B, et al. Gastroparesis and small bowel dysmotility in irritable bowel syndrome. Dig Dis Sci 1997;42:2087-93.

126 Esler MD, Goulston KJ. Levels of anxiety in colonic disorders. N Engl f Med 1973;288:16-20

127 Jorgensen LS, Bonlokke NJ, Christensen NJ. Life strain, life events, and autonomic response to a psychological stressor in patients with chronic upper abdominal pain. Scand f Gasterenterol 1986;21:605-13.

128 Heitkemper $\mathrm{M}$, Jarrett $\mathrm{M}$, Cain $\mathrm{K}$, et al. Increased urine catecholamines and cortisol in women with irritable bowel syndrome. Am f Gastroenterol 1996;91:906-13.

129 Camilleri M, Ford MJ. Functional gastrointestinal disease and the autonomic nervous system: A way ahead? Gastroenterology 1994;106:11147.

130 Gorard DA, Libby GW, Farthing MJ. Ambulatory small intestinal motility in diarrhoea predominant irritable bowel syndrome. Gut 1994;35:203-10.

131 Bazzocchi G, Ellis J, Villanueva-Meyer J, et al. Postprandial colonic transit and motor activity in chronic constipation. Gastroenterology 1990; 98:68693.

132 Camilleri M, Malagelada JR, Kao PC, et al. Gastric and autonomic responses to stress in functional dyspepsia. Dig Dis Sci 1986;31:1169-77.

133 Tack J, Piessevaux H, Caenepeel P, et al. Role of impaired gastric accomodation to a meal in functional dyspepsia. Gastroenterology 1998;115:134652 .

134 Coffin B, Azpiroz F, Malagelada J-R. Selective gastric hypersensitivity and reflex hyporeactivity in functional dyspepsia. Gastroenterology 1991;101: A423.

135 Haug TT, Svebak S, Hausken T, et al. Low vagal activity as mediating mechanism for the relationship between personality factors and gastric mechanism for the relationship between personality factors

136 Hausken T, Svebak S, Wilhelmsen I, et al. Low vagal tone and antral dysmotility in patients with functional dyspepsia. Psychosom Med 1993;55:1222

137 Heitkemper M, Burr RL, Jarrett M, et al. Evidence for autonomic nervous system imbalance in women with irritable bowel syndrome. Dig Dis Sci 1998;43:2093-8.

138 Emmanuel AV, Kamm MA. Laser Doppler measurement of rectal mucosal blood flow. Gut 1999;45:64-9.

139 Stratakis CA, Chrousos GP. Neuroendocrinology and pathophysiology of the stress system. Ann N Y Acad Sci 1995;771:1-18.

140 Drossman DA, Creed FH, Fava GA. Psychosocial aspects of the functional gastrointestinal disorders. Gastroenterol Intl 1995;8:47-90.

141 Veale D, Kavanagh G, Fielding JF, et al. Primary fibromyalgia and the irritable bowel syndrome: different expressions of a common pathogenetic process. Br F Rheumatol 1991;30:220-2.

142 Moldofsky H, Franklin LA, Mayer EA, et al, eds. Basic and clinical aspects of chronic abdominal pain. New York: Elsevier, 1993:249-56.

143 Triadafilopoulos G, Simms RW, Goldenberg DL. Bowel dysfunction in fibromyalgia syndrome. Dig Dis Si 1991;36:59-64. 
144 Spiller RC, Thornley JP, Neal K, et al. Acute and chronic enteroendocrine cell hyperplasia and increased gut permeability in post-dysenteric bowel cell hyperplasia and increased gut permeability
dysfunction. Gastroenterology 1999;116:A1086.

145 García Rodriguez LA, Ruigomez A, Wallander M-A, et al. Detection of colorectal tumor and inflammatory bowel disease during follow-up of patients with initial diagnosis of irritable bowel syndrome. Scand $\mathcal{F}$ Gasterenterol 2000;35:257-307.

146 Chang L, Mayer EA, Johnson T, et al. Differences in somatic perception in female patients with irritable bowel syndrome with and without fibromyalgia. Pain 1999;84.

147 Cook IJ, Van Eeden A, Collins SM. Patients with irritable bowel syndrome have greater pain tolerance than normal subjects. Gastroenterology 1987;93:
727-33.

148 Mayer EA, Naliboff B, Munakata J. The evolving neurobiology of gut feelings. Progr Brain Res 1999;122:195-206.

149 Faris PL, Won Kim S, Meller WH, et al. Effect of ondansetron, a 5-HT3 receptor antagonist, on the dynamic association between bulimic behaviors and pain thresholds. Pain 1998;77:297-304.

150 Naliboff BD, Derbyshire SW, Munakata J, et al. Evidence for decreased activation of central fear circuits by expected aversive visceral stimuli in IBS activation of central fear circuits by expected

151 Drevets WC, Price JL, Simpson JR, Jr, et al. Subgenual prefrontal cortex abnormalities in mood disorders. Nature 1997;386:824-7.

152 Bremner JD, Staib LH, Kaloupek D, et al. Neural correlates of exposure to traumatic pictures and sound in Vietnam combat veterans with and without posttraumatic stress disorder: a positron emission tomography study. Biol Psychiatry 1999;45:806-16.

153 Bremner JD, Krystal JH, Southwick SM, et al. Noradrenergic mechanisms in stress and anxiety: I. Preclinical studies. Synapse 1996;23:28-38.

154 Creed F. The relationship between psychosocial parameters and outcome in the irritable bowel syndrome. Am f Med (Suppl) 1999;107:74-80S

155 Qiu BS, Vallance BA, Blennerhassett PA, et al. The role of CD4+ lymphocytes in the susceptibility of mice to stress-induced reactivation of experimental colitis. Nat Med 1999;5:1178-82.

156 Collins SM, McHugh K, Jacobson K, et al. Previous inflammation alters the response of the rat colon to stress. Gastroenterology 1996;111:1509-15.

157 Kiliaan AJ, Saunders PR, Bijlsma PB, et al. Stress stimulates transepithelial macromolecular uptake in rat jejunum. Am f Physiol 1998;275:G1037-44
158 Shanks N, Harbuz MS, Jessop DS, et al. Inflammatory disease as chronic stress. Ann NY Acad Sci 1998;840:599-607.

159 Gue M, Bonbonne C, Fioramonti J, et al. Stress-induced enhancement of colitis in rats: CRF and ariginine vasopressin are not involved. Am f Physiol 1997;272:G84-91.

160 Million M, Tache Y, Anton P. Susceptibility of Lewis and Fisher rats to stress-induced worsening of TNB-colitis: protective role of brain CRF. Am f Physiol 1999;276:G1027-36.

161 Rao SCC, Holdsworth CD, Read NW. Anorectal sensitivity and reactivity in patients with ulcerative colitis. Gastroenterology 1987;93:1270-5.

162 Chang L, Munakata J, Naliboff BD, et al. Differences in perceptual responses to rectosigmoid stimulation in mild ulcerative colitis and irritable bowel syndrome. Gut 2000 (in press).

163 Bernstein CN, Niazi N, Robert M, et al. Rectal afferent function in patients with inflammatory and functional intestinal disorders. Pain 1996;66:15161.

164 Chang L, Munakata J, Mayer EA, et al. Perceptual responses in patients with inflammatory and functional bowel disease. Gut 2000;47:497-505.

165 Chang L, Derbyshire SW, Munakata J, et al. Perceptual and CNS Responses to visceral pain in patients with inflammatory bowel disease. Soc Neurosci 1999;25:1045.

166 Lidums I, Lehmann A, Checklin $\mathrm{H}$, et al. Control of transient lower esophageal sphincter relaxations and reflux by the GABAB agonist baclofen in normal subjects. Gastroenterology 2000;118:7-13.

167 Mittal RK, Shaffer HA, Parollisi S, et al. Influence of breathing pattern on the esophagogastric junction pressure and esophageal transit. Am f Physiol 1995;269:G577-83.

168 Fass R, Malagon I, Naliboff BD, et al. Effect of psychologically induced stress on symptom perception and autonomic nervous system response of patients with erosive esophagitis. Gastroenterology 2000;118:A637.

169 Wood JD, Peck OC, Tefend KS, et al. Colitis and colon cancer in cottontop tamarins (Saguinus oedipus oedipus) living wild in their natural habitat. Dig Dis Sci 1998;43:1443-53.

170 Willner P. Validity, reliability and utlity of the chronic mild stress model of depression: a 10 year review and evaluation. Psychopharmacology 1997;134: 319-29. 